In the puerperium a severe standard has been adopted, and only those patients whose temperature never reached $99^{\circ} \mathrm{F}$. at any time in the puerperium are counted afebrile.

A rise of temperature to $\operatorname{ror}^{\circ} \mathrm{F}$. on one or two occasions is common after Cæsarian. section.

In my series of 54 cases : It cases were completely afebrile; 12 cases had a temperature on the first day only; 13 cases had a temperature on the first and second days only ; 9 cases had a temperature from three to six days only ; 6 cases had a temperature for longer than six days.

Fifty-two of the wounds healed by first intention.

Two had slight superficial sepsis and were well healed when discharged. All the uteri involuted well. The majority had no lochia when discharged.

Bronchitis occurred in five cases, slight mastitis in two cases, breast abscess in two cases, white-leg in one case, in which the operation had been done after severe hæmorrhage.

Thirty-six of the mothers were able to feed the children entirely on the breast, and forty of the children had more than regained their birth weight when discharged.

The advantages of Casarian section to-day are due, first to the lowered mortality. I feel sure that the mortality in suspect cases can be greatly lowered by adequate disinfection of the vagina and by opening the uterus outside the abdominal wound, and by disinfection of the endometrium, and occasionally by hysterectomy.

Secondly, the ultimate success of the operation is increasing, as there is more knowledge regarding the accurate suturing of the uterus. It is known that it is possible to leave a scar in the uterus after Cæsarian section which cannot be detected even histologically.

Accurate approximation of the cut uterus is required, and perfect asepsis or disinfection, to secure perfect healing.

The best results must always be obtained in the cases which are done early; this applies to every type of case, and though $\stackrel{\mathbb{Q}}{\varrho}$ goo 1 results can be got in late cases, they $c$. can never equal those which are undertaken early.

The best results therefore must ultimately depend on skilled antenatal diagnosis and treatment, and in doubtful cases on consultation with a surgeon with special knowledye of the subject.

In some of the cases the precarious condition of the patients could have been avoided by adequate antenatal treatment. The number of emergency Cæsarian sections ought to diminish as antenatal work in. creases. The more this is done the greater is the patient's chance of having the maximum benefit from the operation, as it enables the operation, when it is necessary, to be done deliberately under the best possible conditions.

\section{A PLEA FOR THE STUDY OF METEOROLOGICAL CONDITIONS IN RELATION TO OPEN-AIR TREATMENT AND TUBERCULOSIS.}

\author{
$B y$ A. NIVEN ROBERTSON, \\ M.D., M.R.C.P., D.P.H. \\ Medical Superintendent, Derbyshire County \\ Sanatorium.
}

IT goes without saying that all of us are interested in the weather. Every human being and every animal feels its influence. N Indeed many of the lower animals seem to be more sensitive to weather changes than human beings. They appear to be able to 0 detect and predict certain changes even before the most accurate scientific instruments give any indication and one would? sometimes feel inclined to think that they have certain means of knowledge and 
certain senses that we are without. Or perhaps are their senses only more acute?

Have we as open-air physicians studied the effect of open air scientifically in the same way as we have analysed the effect of any drug or physic? I scarcely think we have.

Open air has been the method of treating consumption for about forty years but the attempts to show in a scientific manner what it is in open air that produces its good. effects have been few. The observations in relation to the effect of meteorological conditions upon open-air patients are relatively few and far between. Most previous observers have used as an index of the effect on metabolism the weekly gain or loss in weight of the patients and I have followed on their lines, but whether these are the right lines or not is questionable. Such investigations have been made by Henderson Smith at Mundesley, Lunde of Norway, de Bloeme of Holland, Guipenberg in Finland, Sargo in Austria and Burns in America. More recently, Strandgard, of Boserup Sanatorium, Denmark, as a result of the study of the weekly average gain of patients in eight different Danish sanatoriums for a period of over ten years, found that the variations in weight in the different institutions were similar with minor differences, and he attributed the variations to the influence of climate. He found the weight curve ran parallel with the amount of sunlight, atmospheric temperature and rainfall, but he was unable to solve the part that each of these played. Comparing his observations with those of the previous observers mentioned he pointed out that in every case the maximum gain of weight was in autumn. In Norway the maximum was reached in August, in the rest of Europe in September, in Pennsylvania in October and in India in November. It seemed that the maximum shifted from August to November as the different sanatoriums were traced from north to south. The gain of weight was greater in cold countries than in hot countries, and the latter showed a greater gain in winter. In Denmark the months with maximum gains of weight were the months with low barometric pressure, bigh rainfall and moderate temperature. Strandgard also concluded that humidity had much to do with the weight variations.

Möller, at his sanatorium in South India, found the greatest gain in November coincident with the rise in rainfall and fall in temperature. His patients lost most in March, April and May, the hottest months of the year, with an average temperature of $82^{\circ} \mathrm{F}$., whereas the patients in Northern Europe gained most in the hottest months of autumn. He attributed the gain in November to the absence of oppressive heat and sunshine, and the cooling power of the rain and increased humidity.

As the result of reading Professor Leonard Hill's wonderful book on the Science of Open-Air Treatment, which I found to be a veritable treasure house of all the facts known relative to man's aerial environment, I realized that for ten years I had been using open air daily as a therapeutic agent and knew very little about it. Hill with his? katathermometer completely revolutionized our views regarding ventilation and air conditions and he rightly regarded his katathermometer as a "meter" of the "living" atmosphere. It is a measurer of the cooling power of the air which is not a single "dead" factor as the other factors such as temperature, humidity, \&c., are, but is the sum of the temperature, wind humidity, sunshine, rainfall and all the combined forces of the atmosphere together. With this new and greatly superior measurer of atmospheric conditions one felt compelled to review the observations of these previous observers and therefore for the last five years I have made daily records of the cooling power of the air by the wet kata and dry kata by Leonard Hill's katathermometer.

At the same time I have made daily records of the temperature, relative humidity, rainfall, barometric pressure, note of direction of the wind, note of cloudiness or 
brightness of the day, rate of wind in miles per hour, the amount of ultra-violet light and the amount of radiant heat by black fur temperatures. Maximum and minimum temperatures have also been recorded daily. As we could not afford an anemometer and wind vane till recently the rate of wind was estimated from the kata readings by Hill's formula. The amount of ultra-violet light was estimated by Hill's methylenè-blue gauge, the accuracy of which is questioned by some although not by Hill himself. Since March, I928, when I could afford a sunshine recorder records of hours of sunshine have been made. The average weekly gain or loss of weight has also been charted.

I believe they confirm Professor Leonard Hill's general contentions. On page 93 of his book he says, "There is evidence then that not only does a higher cooling power increase the metabolism during exposure but it raises the basal metabolism to a higher level. Largely in this lies the benefit of open-air treatment of children and consumptives." It was largely to prove or disprove these words to my own satisfaction and by careful scientific investigation that I siarted this piece of research. As far as a workingclass sanatorium is concerned I believe it is only a half truth, as you will see by my later remarks. It might apply to a sanatorium catering to the wealthier classes and I would welcome a similar investigation in such a type of sanatorium for this reason. I cannot confirm the observations of the Danish investigators. Wind goes up and down relatively independently of the weights, rainfall does the same and the relative humidity and temperatures follow their respective curves independently of the weights. One might expect that sunny days would influence appetites-we all feel brighter on sunny days and I certainly notice patients do-but it has no manifest effect on the weight curve nor has the direction of the wind apparently. In the kata curves and the weight curves there is a definite co-relationship. In winter when the kata goes up so that there is excessive cooling power the weights go down and to a certain extent when the kata falls the weights rise. In summer on the other hand you have the reverse, when the kata goes up the weights go up and when the kata falls the weight falls. To this latter rule the summer of 1927 was an exception, but you will remember 1927 had no summer. There was a very small amount of radiant heat and ultra-violet rays in the summer of 1927, with a low average summer ordinary temperature.

In winter there is great oscillation in the kata curves but in summer these curves are steady; so you have quite typical winter and and summer kata curves. To a certain extent as evidenced by the above rules you have typical summer and winter weight curves correlated with the kata curves for these two seasons.

During 1923 and 1924 the weight curres also oscillated less in summer than in winter and at first I had the impression this was to be a general law; but the weather is fickle as we know and after careful scrutiny I finde that the variations of weight are as frequent in summer as in winter, but the excessive oscillations in weight certainly occur in autumn and winter.

What is the cause of these two rules regarding summer and winter katas and summer and winter weights?. In winter where patients are poor and cannot or will not use sufficient warm clothing, they often shiver, get depressed metabolism with excessive cooling power and thus lose weight. The patients who are not fit for exercise but who are fit to be out of bed are always a problem in winter as they feel the cold so much. It is a question whether warmer rooms should not be provided for them to rest in. This I have done this winter, and unless it is done, the true rest régime is difficult to carry out in at least a cold, exposed, working-class sanatorium. In summer, however, the kata going up, there is greater cooling power, the metabolism is enhanced and the patients feel 
cooler and refreshed and gain weight. They lose when the cooling power falls and it is too hot.

There is, I must admil, some relationship between marked rise of wind and fall of weight: with marked rise of wind there were twenty-three weeks with loss of weight and sixteen with gains.

With fall of wind it was reversed there being thirty-one gains to twenty-three losses. This relationship corresponds with the kata: high katas, high wind-fall of weight especially in winter; fall of wind, low kata - gain in weight.

Now relative to months and weights let us examine the monthly chart. Here I am to a certain extent in agreement with Strandgard and the other observers, that the greatest gain in weight is in the autumn months. In the years of $1924-25-26$, the maximum gains were in the autumn, August, September and October. The total gain in five years in August was rgo oz., in September, 2 ro oz., and in October, 2-13 oz., compared with values I30-160 in nearly ail the months of the year, except December, with $216 \mathrm{oz}$.

I think the cause of the gain in autumn is the combination of moderate cooling power and moderate radiant heat, the two desiderata most necessary for increased metabolism according to modern ideas of physiological ventilation. The year r927 was again an exception. In that year the greater gain was in both November and December, but in that year we had no radiant heat worth speaking of. The great gain in December is to my mind rather in conflict with Professor Hill's theory. There is no radiant heat and the cooling power is excessive. Possibly Christmas fare and extra gifts of dainty food from frieinds at that season render this month deceptive. There is also the psychological effect of Christmas on appetite. There were big gains of weight in Christmas weeks in 1924 and 1925 which account for some of this gain, but not all. The gain in this December, I92x, may be partly due to the fact that it was relatively a mild December.
These observations only cover a period of five years, but meteorologists, before they assess the normal weather conditions of any given place, require observations over a ten year period, and I am quite sure that the same period is probably required before we can judge the average effect of these normal conditions upon our patients. Not only is this period of time required, but team work is necessary, not only observations at one or two sanatoriums but at all sanatoriums throughout the country. If this were done I am sure we will learn many useful facts concerning the effect of the various factors of open air upon our patients. In this way one could have a meteorological census of our sanatoriums or perhaps it should be termed a meteorological directory of sanatoriums. If done on a international basis it would be still more interesting as the climates would be still more various.

Now what are the observations and instruments required? They are :-

( 1 ) Wind by Robinson's Anemometer.

(2) Wind direction by wind vane.

(3) Rainfall by rain gauge.

(4) Relative humidity by psychrometer.

(5) Pressure by barometer.

(6) Temperatures ordinary maximum and minımum.

(7) Cooling power by kata thermometer.

(8) Radiant heat by black fur temperatures or"solar radiation thermometers.

(9) Ultra-violet light by Hill's methyleneblue gauge.

(Io) Sunshine by sunshine recorder.

(i I) Record of dull and bright days.

Dr. Goodchild suggested also dust counts.

If these observations are to be comparative I think they ought all to be done, if possible, with an accuracy that would satisfy the Meteorological Office. As a society of scientific men we ought to be able to give information that would be of some value to another body of scientific men, viz., the Royal Meteorological Society. The Meteorological Office require a Kew pattern barometer and the pressure readings to be corrected for latitude, altitude, temperature 
and index error. For sunshine they require a Campbell-Stokes sunshine recorder adjusted for level, meridian and latitude. The Jordan is really a sunlight recorder. One of their pattern rain gauges should also be used. Our vade-mecum would be the Meteorological Observer's Handbook.

We would be what are termed Auxiliary Meteorological Stations with additional observations specially applicable to our medical purposes, such as the kata and radiant heat. The readings would require to be taken at the same time at all places. The cost of the set of instruments required is about $£ 34$. Hick's set of instruments, as required for observatories, is about $t_{2} 29$. Of course, you can spend much more if you get continuous self-recording barographs, thermographs, hygrometers, rain gauges, Dines' wind-pressure anemometers, \&c. You can get a continuous self-recording kata for 635 . These, if you have the money, save time and labour but are not at all necessary.

For estimating effect of barometric pressure on occurrence of hæmoptysis a barograph is almost essential and I have not gone into this question. The daily time taken by me is now very little because I have taught my laboratory assistant to do all that is required. It only takes about thirty minutes of his daily time and he is an old patient.

I think you will admit that at present open-air treatment is mainly empirical and that there is too much open-air treatment en masse. The climate that suits one patient does not suit another. An early ambulant case does well in an exposed, bracing atmosphere, with a high cooling power; the chronic bronchitic and the advanced case do better in a warmer, more equable air. The treatment of the acute pneumonic is a debatable question. Chronic emphysematous cases and asthmatics are very sensitive to air variations. Hundreds of tuberculous patients with these every-day secondary complications are sent indiscriminately into sanatoriums. As soon as a diagnosis of tuberculosis is made, patients of every grade and type are dumped into a sanatorium with an environment often eminently suitable only for early afebrile cases, for which type of case most sanatoria were originally constructed. Often nobody is to blame. It is the only place available. Often there is $\stackrel{\varnothing}{\circ}$ no time to find out that a case has perhaps also albuminuria due to nephritis requiring $\overrightarrow{0}$ some degree of warmth, or has frequent attacks of acute rheumatism, which are $\vec{\omega}$ aggravated by the cold, damp air of a sanatorium. Much also depends on the rigidity of our local schemes. All patients in Derbyshire must go to the sanatorium in Derbyshire. The climate of Derbyshire is not one suited to the chronic bronchitic. The rich seek climates in Davos, Arosa, Kenya, Egypt, or even Denver or Samoa. I think the Ministry ought to allow at least a little latitude in our local schemes and some provision for certain cases at least securing th $\vec{\sigma}$ climate that suits them best. It may be argued that the amount of variation in oxpo British climate is too little to have any effect, but $l$ think this is not quite true. The average duration of sunshine in June on the South coast of England is seven and a half hours compared with six in the North, and the average yearly duration is $4 \frac{1}{2}-3 \frac{1}{2}$ respectively. In December the English Channel gets double the sunshine of the Pentland Firth. The largest recorded extreme variation of temperature in London is $96^{\circ} \mathrm{F}$., and for Stornoway, $67^{\circ} \mathrm{F}$. So also in the case of rainfall. Seathwaite, Cumberland, has 189 in. per annum, and Norfolk 9 in. Al- 9 though the climate is on the whole equable, $D$ there are definite enough variations to affect the sanatoria in different areas of Great $\stackrel{N}{\circ}$ Britain. By our Meteorological Directory N of Sanatoria we could choose by scientific criteria the sanatorium with the climate most suited to the type of case.

Still more I believe that there are even great local variations dependent on degree of shelter, proximity to cities and dust, \&c. 
This is noticeable in studying the botany of one's district from an ecological standpoint. One notices every year on a certain sunny bank certain flowers grow and bloom earlier. If the area is sheltered by a high chalk cliff as in the Isle of Wight undercliff, there is so much radiant heat that it is too hot in summer, while on the top of the clitf it may be quite pleasant. I am sure the cooling power figures at different sanatoria would give food for reflection. I think I have less hæmoptysis in Walton Sanatorium than I had in Benenden, because of the high cooling power and exposure. In early congestive cases with a hæmorrhagic tendency I am sure the exposed bracing site is the best. It draws the blood to the skin and depletes the larger viscera. Cases with old chronic fibrosis, curved finger-nails and tendency to cyanosis and dyspnœa cannot stand the cold open air of winter in an exposed site with high kalas. I believe some of them would do as well at home. Sir Henry Gauvain has shown how some of his cases do best inland and others on the sea coast even in the same county. Too little attention has been given to meteorology in choosing the site of many sanatoriums. Surely it should be the first consideration, but it has often been neglected for consideration of cheapness of site or even more trivial causes. I would, in passing, include geological suitability. I know many sanatoriums placed exposed to violent rainbearing winds with the result that half the days of the winter the windows must be closed.

Sometimes I am a little sceptical about open-air treatment as it is practised. As superintendents we are apt to treat all our patients more or less alike with the same environment simply because we are forced to do so or perhaps out of laziness to find the best environment for each type of case. Not long ago I had four patients all over 55 and all "cleared out." Sometimes I wonder it it wouldn't be preferable to warm our cubicles and allow fresh air to get in to our nude patients, exposed to radiant heat from a good fire to prevent chill if there is any truth in Hill's teaching. I would like to experiment with some in a warm ward and others in an ordinary cold sanatorium ward to compare results. When sanatorium treatment first came in did rest régime come in with it and were the good results of rest put down to fresh air? Does fresh air produce only a skin-deep effect? Have we been deceived by this appearance? Patients at once begin to get colour, look rosier and better, but P.s don't change. Soon after discharge their pallor often reappears. Did not most of us when qualified find the only places regarded as suitable for treating $\mathrm{TB}$ cases were sanatoriums and accepted these conditions to treat them there? Can any of us compare the "Sanatorium epoch" with the time before it to explain fully if and how open-air treatment has improved our results?

I trust that I have made out a case for a combined research into the science of openair therapy, that we may remove the ban of empiricism from the mainstay of sanatorium treatment, and that we as sanatorium superintendents may be able to state clearly what factors in open air are beneficial and how open air improves our tuberculous patients. My own observations are a mere drop in the bucket, they refer to only a block of fifty male early and medium types of cases. They only cover a five-year period, and. before one can speak definitely we must have ten. year normals and results from many sanatoriums in varied climates.

It is difficult to separate out the factors that may influence weights such as the type of case being admitted in the same block from period to period, although there was a general average in the cases I have discussed. When patients become toxic and begin to lose weight rapidly of course, such an event would spoil the records. As these are put on absolute rest and are not weighed I have eliminated this error. Also I have excluded all weights of patients in their first two weeks 
of residence, as half the total weight is gained in these first two weeks and I felt this would create an error in finding out the influence of the various open-air factors on the general mass of cases. I may have been wrong in this because it is during this period that the change from their homes to complete fresh air occurs, and perhaps it is by studying this period that one would find the real cause of the benefit of fresh air. To do this properly of course one would have to take these records in the patients' homes for two weeks before admission and then compare. This is of course difficult to do but the tuberculosis officer might assist in this direction. A scrutiny of the meteorological conditions of a county in relation to the morbidity and mortality of tuberculosis in the county could be done by a county tuberculosis officer and would be of great value. It has been done in relation to rainfall by Dr. Gordon of Exeter, in relation to Devon and Derbyshire, and in India by Sir Leonard Rogers. Why is there such a high death-rate from tuberculosis in the Isle of Lewis? Granted it is partly due to poverty of the inhabitants, but it also may be clue in great part to climatic factors, the great rain and fierce wind of the Atlantic.

We do not really know the value of the different factors in the air on the human system, healthy or diseased. Our ancestors believed in living under a lucky star. I am not going so far as to say we should find out which star suits each patient and put his bed in the meridian of his appointed star. Yet on the other hand Professor Millikan has studied the cosmic radiation from nebulæ, the embryoplasm of stars which penetrates 5 yards of lead, and Professor Jeans says this radiation is the most fundamental physical phenomenon of the whole universe. Our bodies are traversed by it night and day and it is so intense that it breaks up several millions of atoms in each of our bodies every second. 'To escape it we must go down in a submarine or into a mine. How many of us ten years ago would have dreamed that we in London could hear and see people speaking in America? Surely then there is much to learn from a scientific $\frac{\varrho}{\zeta}$ research into the medico-physics of open-air treatment.

\section{CRIME AND INSANITY. LECTURE III.}

given at THE maUdSLey hospital, may $14,1929$.

By W. NORWOOD EAST,

M.D., M.R.C.P.

Medical Inspector, H.M. Prisons, England and Wales. ํㅓㅁ

\section{. (Continued from p 27)}

CRIME is frequently associated with de- $\overrightarrow{0}$ mentia præcox, and it may be difficult to $\mathbb{\mathbb { D }}$ distinguish between the symptoms due to $\stackrel{\Phi}{7}$ the simple or hebephrenic type of the $\underset{\mathbb{D}}{-}$ disease and those of mental deficiency, par $\overrightarrow{0}$ ticularly when both conditions occur in the 응 same offender. A gradual change in person. ality, accompanied by increasing apathy; foolish behaviour, a withdrawal from reality, mild depression, occasional emotional outbursts and impulsions, and progressive mental deterioration suggest dementia præcox. But Tredgold ${ }^{1}$ points out that certain types of retrogression in mentally defective persons correspond in all essentials to the simple type of dementia præcox, and to the dementia due to senility. In criminal cases associated with dementia præcox prolonged observation may be necessary before an accurate diagnosis can be made. $\dot{A}$ man, 은 aged 23, was in the VI standard on leaving $D$ school, and was afterwards engaged for a short time as a porter, and then for three o years as a carman. He served for two and N a half years in the Army during the war, and $\mathrm{C}_{\mathrm{N}}$ was for some months in a hospital under treatment for neurasthenia. On discharge

1 "The Relationship of Mental Deficiency to Mental Disease in General." A. F. Tredgold, 